\title{
PERFIL DA SOCIEDADE NATALENSE FRENTE AOS RESÍDUOS SÓLIDOS URBANOS SOB O OLHAR DO GARI
}

\author{
B. S. RODRIGUES ${ }^{1}$ A. D. D. S. A. DE GÓES ${ }^{1}$ e Y. J. FERNANDES
${ }^{1}$ Controle Ambiental do Instituto Federal de Educação, Ciência e Tecnologia do Rio Grande do Norte (IFRN)
brunnasr@ig.com.br - aja.devidasi@gmail.com - ynarajakelinne@yahoo.com \\ Artigo submetido em agosto/2011 e aceito em abril/2014 \\ DOI: $10.15628 /$ holos.2014.654
}

\section{RESUMO}

O presente trabalho tem como objetivo mostrar uma análise crítica referente a postura da sociedade da cidade do Natal/RN diante dos resíduos sólidos urbanos por meio do olhar do gari. As pesquisas se baseiam no estudo da percepção de garis que trabalham em quatro locais distintos, sendo estes: $O$ Instituto Federal de Educação, Ciência e Tecnologia do Rio Grande do Norte - IFRN Campus Natal Central, o Parque das Dunas, o centro comercial do Alecrim e a praia de Ponta Negra, onde os
25 garis foram entrevistados individualmente tendo por base uma entrevista semi-estruturada. Através das análises das respostas obtidas percebeu-se que a população natalense seja ela infantil, jovem ou adulta necessita que uma educação ambiental seja trabalhada a fim de que o quadro relacionado aos resíduos mude, melhorando, portanto, a qualidade do meio ambiente e da vida das pessoas.

PALAVRAS-CHAVE: lixo, percepção, gari, educação ambiental.

\section{COMPANY NATAL'S PROFILE FRONT URBAN SOLID WASTE IN THE LOOK OF STREET SWEEPER}

\begin{abstract}
This article aims to show a critical stance regarding the society of the city of Natal / RN in front of municipal solid waste through in the look of street sweeper. The research is based on the study of perception of street cleaners who work at four separate locations, namely: The Federal Institute for Education, Science and Technology of Rio Grande do Norte - IFRN Campus Natal Central, the Parque das Dunas, the mall's Alecrim and the Ponta
\end{abstract}

Negra beach, where they were interviewed individually based on a semi-structured interview. Through the analysis of the responses it became clear that Natal's population either child or young adult who needs an environmental education is crafted so that the picture changes related to waste, improving therefore the quality of the environment and life people.

KEYWORDS: garbage, perception, street sweeper, environmental education. 


\section{INTRODUÇÃO}

Os resíduos sólidos urbanos, mais conhecidos como lixo, constituem uma preocupação ambiental mundial, especialmente em grandes centros urbanos de países subdesenvolvidos. A geração de resíduos, geralmente proporcional ao crescimento populacional, suscita uma maior demanda por serviços de coleta pública, e esses resíduos, se não coletados e tratados adequadamente, provocam efeitos diretos e indiretos na saúde, além da degradação ambiental (SANTOS; SILVA, 2009).

Contraditoriamente, o povo brasileiro costuma preocupar-se com a sua higiene pessoal, a limpeza da sua casa, sua calçada; entretanto, fora de seus limites deixa de se importar com os destinos do lixo nas vias públicas. As pessoas não consideram o espaço público como extensão da sua casa. Conforme Tavares \& Freire (2003), essa atitude ocorre pela dificuldade da população em considerar "preservação do meio ambiente" um conceito próximo do seu dia-a-dia - o que inclui a rua, o bairro, a cidade -, associando-o somente à proteção de animais e florestas.

Segundo Portilho (2006), a sociedade se relaciona com os resíduos dentro de um quadro de afastamento e alienação, carregado de preconceitos e estigmas. O lixo, apesar de estar à margem, cumpre uma função significante ao testemunhar o que a sociedade não quer ser. Assim, através de sensibilidades negativas com relação aos restos, historicamente construídas, surge o desejo de afastamento, ou seja, queremos sempre estar bem longe do lixo, da sujeira, das pessoas e espaços a ele relacionados e de todas as suas ameaças e perigos.

Para remover qualquer preconceito da sociedade para com o lixo é necessário conhecê-lo, uma vez que apenas quando conhecemos algo, podemos tomar conclusões a respeito. Para Ferreira (2000), lixo é tudo aquilo imprestável. O conceito dicionarizado e de conhecimento de toda a população não atrai a atenção social para a busca de compreender seus significados, envolvendo desde os seus aspectos positivos, quando considerado uma fonte de energia e materiais reciclados, aos seus famosos aspectos negativos.

O lixo, portanto, tem papel especial. É dele que deriva o bem-estar da sociedade. Por ser o produto principal e mais abundante desse tempo, resultado final de toda e qualquer ação de consumo, descartar tudo o que se tornou obsoleto é medida de satisfação, é garantia de estar fora do lugar onde ninguém quer estar. Assim, o lixo é considerado, na sociedade contemporânea, o local dos excluídos e rejeitados, dos indivíduos estigmatizados (CUNHA, 2009).

Buscando não cair nas denúncias das condições de vida do "povo do lixo", a produção desse artigo propõe compreender os valores dos garis, dentro de uma pesquisa de abordagem quantitativa e natureza descritiva, investigando a ordem dos saberes e as práticas cotidianas. Nesse contexto, nasce o presente estudo, o qual visa, através da percepção do gari, expor uma análise crítica sobre a postura da sociedade natalense com as questões socioambientais envolvendo resíduos sólidos urbanos. 


\section{REVISÃO DA LITERATURA}

\subsection{POSTURA DA SOCIEDADE COM AS PROBLEMÁTICAS DO LIXO}

Assim como Galbiati (2005), a Organização Mundial da Saúde (apud PNUD, 2004) define lixo como "qualquer coisa que seu proprietário não quer mais, em um dado lugar e em certo momento, e que não possui valor comercial". De acordo com essa definição pode-se presumir que o "lixo" separado nas residências não seria de inteiro lixo, todavia a maioria das pessoas se quer tem noção desse conceito o que dirá da destinação e das várias utilidades que são possíveis para esses resíduos.

Todos os fatos relacionados com a crise ambiental atual foram produzindo uma mudança gradativa na sociedade e nas suas instituições. Mas dependendo de como essas informações penetram nas percepções dos indivíduos e de como se refletem em suas ações, as mudanças acabam sendo lentas e incompletas. Assim, em uma mesma organização social podemos encontrar, convivendo lado a lado, posturas conservadoras, indiferentes ou renovadoras (OLIVEIRA; CORONA, 2008).

Quadro 1: Posturas dos grupos sociais frente às questões ambientais

\begin{tabular}{cl}
\hline Postura & \multicolumn{1}{c}{ Descrição } \\
\hline $\begin{array}{c}\text { Ausência da consciência em } \\
\text { relação às responsabilidades }\end{array}$ & $\begin{array}{l}\text { O lixo é um mal necessário, símbolo do processo tecnológico } \\
\text { e elemento obrigatório de suas atividades }\end{array}$ \\
$\begin{array}{c}\text { Consciência sem } \\
\text { comprometimento }\end{array}$ & $\begin{array}{l}\text { Atitude reativa: faz apenas o necessário a fim de evitar } \\
\text { multas e punições }\end{array}$ \\
Comprometimento & $\begin{array}{l}\text { Responsabilidade coletiva (postura proativa) } \\
\text { Responsabilidade social e ambiental; gerando atitudes que } \\
\text { promovam suporte e equilíbrio no uso e manutenção dos } \\
\text { nossos recursos }\end{array}$ \\
\hline
\end{tabular}

Fonte: OLIVEIRA; CORONA, 2008. Com adaptações.

Para Melazo (2005), o ambiente natural assim como os ambientes construídos é percebido de acordo com os valores e as experiências individuais dos homens onde são atribuídos valores e significados em um determinado grau de importância em suas vidas. A percepção individual ocorre através dos órgãos dos sentidos associados a atividades cerebrais. As diferentes percepções do mundo estão relacionadas às diferentes personalidades, à idade, às experiências, aos aspectos sócio-ambientais, à educação e à herança biológica.

Oliveira e Corona (2008) consideram ainda que as diferentes visões e posturas frente à problemática ambiental, principalmente quando voltada aos resíduos sólidos urbanos, decorrem das diferentes maneiras de se compreender a questão ambiental. Diferenças nas posturas que são reveladoras de diferentes noções e interpretações científicas sobre o meio ambiente.

Além disso, a ética tem papel fundamental no comportamento ambiental da sociedade. É a partir dela que se constroem os valores humanos. Desde pequenos somos ensinados sobre o certo e o errado e um de nossos ensinamentos é cuidar de nossa casa e de todos os que estão ao nosso redor. Porém muitos não vêem as ruas ou os lugares por onde andamos como parte de nossas residências ou não imaginam que todos os animais e plantas também fazem parte desse círculo de 
seres que merecem a nossa atenção e, por isso, cuidam, apenas, de sua moradia e de seus familiares e isso acaba por corroer todo o ecossistema ao seu redor.

Carvalho (2004) diz que a visão socioambiental orienta-se por uma racionalidade complexa e interdisciplinar e pensa o meio ambiente como espaço relacional, em que a presença humana aparece como um agente que pertence à teia de relações da vida social, natural, cultural e interage com ela.

\subsection{EDUCAÇÃO AMBIENTAL E RESÍDUOS SÓLIDOS}

Educação ambiental implica em ensinamentos que nos levem a uma percepção mais sensível do ecossistema como um todo. De acordo com Carvalho (2001) a educação ambiental vem sendo incorporada como uma prática inovadora em diversos âmbitos. Entretanto, a população ainda não incorporou, de fato, esse dever.

Segundo BRASIL (2004) a questão do lixo pode ser trabalhada em programas de educação ambiental, desde a perspectiva do "Lixo que não é lixo" em que o eixo central de abordagem está na contestação do consumismo e do desperdício, com ênfase na ação individual por meio dos três $\mathrm{R}$ (reduzir, reutilizar e reciclar), até aquela que toma esta problemática como conseqüência de um determinado tipo de relação sociedade - natureza, histórica e socialmente construída.

Como meio de tratar adequadamente dos resíduos sólidos, o Brasil possui legislações e normas específicas. A questão dos resíduos sólidos de acordo como é citada na Constituição Brasileira no artigo 225, que dispõe sobre a proteção ao Meio Ambiente; na Lei no 6.938/81, que estabelece a Política Nacional de Meio Ambiente; na Lei no 6.803/80, que dispõe sobre as diretrizes básicas para o zoneamento industrial em áreas críticas de poluição; nas resoluções do Conselho Nacional de Meio Ambiente - CONAMA 257/263 e 258, que dispõe sobre pilhas, baterias e pneumáticos; na Agenda 21 (Rio-92) nos capítulos 19, 20 e 21 e mais recentemente os resíduos sólidos têm sido discutidos através da lei no 12.305/10 que institui a Política Nacional de Resíduos Sólidos (PNRS).

Nesse momento entra um dos papeis da educação ambiental que é o de promover à população o acesso a tais leis, artigos e normas, difundindo-os em diversos meios para que possam atingir a massa como, por exemplo, a televisão, os jornais e a internet e que leve as pessoas a desenvolver um senso crítico a respeito do tema, gerando novos paradigmas da qualidade ambiental.

Mesmo a população tendo o desejo de agir de acordo com a educação ambiental e a sustentabilidade isso não é inteiramente possível se há falta de um dos requisitos principais para essa tarefa, os conhecimentos básicos sobre os resíduos e seus diferentes tipos de descarte. Conforme Noronha (2005) é comum as pessoas confundirem os termos "Coleta Seletiva" com "Reciclagem". Além de não haver uma compreensão das lixeiras para resíduos recicláveis, uma vez que muitas pessoas trocam os locais dos metais e dos vidros ou dos papéis e plásticos. Isso torna a disposição desses recipientes inúteis nos locais, pois os resíduos se misturam e não há, de fato, uma coleta seletiva eficiente.

Considerando que parte dos resíduos gerados pelas atividades humanas ainda possui valor comercial, se manejado de maneira adequada, deve-se adotar uma nova postura e começar a ver o lixo como uma matéria-prima potencial. Sendo assim, considerando a complexidade das 
atividades humanas, pode-se verificar que resíduos de uma atividade podem ser utilizados para outra, e assim sucessivamente (D`ALMEIDA; VILHENA, 2000).

\subsection{GARI - PROFISSIONAL DE OPERAÇÕES DE LIMPEZA E SERVIÇOS URBANOS}

Segundo BRASIL (1982), os garis são profissionais que efetuam a limpeza de ruas, parques, jardins e outros logradouros públicos, varrendo-os e coletando os detritos ali acumulados, para manter os referidos locais em condições de higiene e trânsito. No entanto, o presente estudo foi desenvolvido com garis e trabalhadores de serviços gerais (conservação, manutenção e limpeza), e a terminação gari será utilizada para referir-se a tais profissionais.

A atuação profissional desses funcionários públicos, na maioria das vezes, não é reconhecida pela população, que os vê como inferiores ou subalternos, já que trabalham sujeitos à insegurança, às condições inadequadas e lidam diretamente com algo discriminado pela sociedade, o lixo. Em contrapartida, o trabalho dos garis é de fundamental importância tanto para a saúde e bem estar da sociedade civil, como para as questões de saneamento básico de uma cidade e estética da mesma.

De acordo com Sgorlon et al. (2008), essa visão deve ser mudada. O trabalho dos garis é muito mais do que a limpeza das vias públicas. É a manutenção do ambiente social em que a população desenvolve todos os seus projetos, sejam de trabalho, de relacionamento ou de convivência. A profissão de gari é um trabalho digno, árduo e honesto como muitos outros e deve ser reconhecida como tal. A importância do limpador de rua não pode ser esquecida ou inferiorizada.

Ainda que grande parcela da sociedade considere esses profissionais como ignorantes, todos os entrevistados eram alfabetizados e 50\% tinham concluído o Ensino Médio, dentre eles um estudou na antiga Escola Técnica Federal do Rio Grande do Norte (ETFRN), escola bem conceituada na capital. Essa é a realidade. Diante do que foi exposto e confiando no potencial desses trabalhadores, a pesquisa é desenvolvida sob a ótica deles.

\section{METODOLOGIA}

O presente artigo, realizado entre maio e junho de 2011, envolveu a participação de 25 trabalhadores que executam o serviço de limpeza pública, dentre eles, garis (10) e auxiliares de serviços gerais (15), enriquecida pela observação e análise crítica das autoras. Os entrevistados eram alfabetizados e apresentaram uma faixa etária média de 36 anos de idade.

Como unidades de estudo, foram escolhidas quatro locais de diferentes importâncias no município, a fim de estabelecer um elo comparativo e verificar se ocorreria alguma diferença nos resultados. O Instituto Federal de Educação, Ciência e Tecnologia do Rio Grande do Norte (IFRN) Campus Natal Central foi escolhido como Centro de Ensino, onde normalmente se encontra jovens e adultos; o Parque das Dunas, como Patrimônio ambiental do município e é visitado por pessoas de todas as idades; o Alecrim, o centro comercial mais ativo da cidade, onde há a circulação intensa de adultos; e a Praia de Ponta Negra, lugar de prestígio dos turistas. As entrevistas foram realizadas individualmente nos locais de trabalho dos profissionais, de tal forma que não prejudicasse o desenvolvimento de suas tarefas. 
Como instrumento de coleta de dados, utilizou-se a entrevista semi-estruturada (BONI; QUARESMA, 2005), abrangendo o olhar do trabalhador sobre a postura da população natalense quanto aos resíduos sólidos urbanos e à sua respectiva inserção nesse meio, sua posição quanto às soluções propostas e alguns dados pessoais que poderiam interferir nas respostas (como grau de escolaridade, idade).

A entrevista individual semi-estruturada representou uma forma de interação social entre o entrevistador e os entrevistados, pois, segundo Brandão (2000), a entrevista é trabalho e como tal reclama uma atenção permanente do pesquisador aos seus objetivos, obrigando-o a colocar-se intensamente à escuta do que é dito, a refletir sobre a forma e conteúdo da fala do entrevistado.

\section{RESULTADOS E DISCUSSÃO}

Nas pesquisas realizadas optou-se por ter como um dos questionamentos o conceito do termo "lixo", tendo em vista que assim poderia ser avaliado o quão aprofundado esse grupo de trabalhadores está com relação ao seu próprio ofício. A partir disso foi constatado que $76 \%$ dos garis têm uma visão de que lixo é tudo o que não tem mais utilidade, $12 \%$ definiram como "algo que não serve para uns, mas serve para outros" e obteve-se, também, 12\% para as respostas: lixo é tudo o que está presente no mundo, lixo é algo intermediário, sujo ou rejeito.

Com isso ficou claro que o conceito de lixo não é totalmente concretizado na mente da população e, principalmente, na dos garis, pois ao fazer essa pergunta todos eles se mostraram um pouco confusos e pensativos antes de respondê-la. Assim, é necessário um maior investimento na qualificação do gari com relação à compreensão do seu próprio trabalho e o mesmo na educação para a formação de crianças críticas que possam compreender, a partir de seus conhecimentos e suas análises, certos conceitos que ainda estejam mascarados aos seus olhos para que, no futuro possam ser pessoas, com o ofício de gari ou não, com conceitos definidos e conscientes.

Ao serem interrogados sobre os tipos de resíduos mais encontrados nos locais cerca de $26 \%$ dos garis afirmaram ser papel, $29 \%$ plástico, $14 \%$ foi constatado para vidro, $14 \%$ metais e $14 \%$ também para lixos orgânicos e $3 \%$ deles afirmaram ser outros tipos de lixo como é o caso dos cigarros, como representado na figura 1.

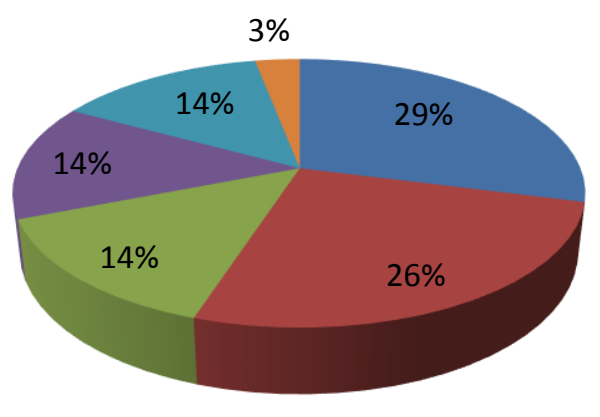

Plástico
Papel
Vidro
Lixo orgânico
Metal
Outros

Figura 1: Percentual da composição do lixo produzido pela sociedade natalense nos locais onde foram realizadas as entrevistas.

Por conseguinte é possível verificar que a população apresenta um nível muito elevado de consumo, que, em muitos casos, é devido ao sistema capitalista e aos modismos, agredindo drasticamente o ecossistema. É notório também que falta à população natalense o conhecimento 
específico sobre cada objeto descartado e quanto tempo ele leva para a sua decomposição como o plástico que demora cerca de 450 anos para se decompor, porém é o objeto mais utilizado pelo universo natalense e até mesmo por todo o mundo, tendo em vista que hoje, quase todos os produtos industrializados contêm plástico e isso torna quase inevitável a utilização desse objeto. Todavia, é totalmente viável diminuir a quantidade de resíduos gerada por cada um, basta haver um enfoque maior do governo com relação ao aprendizado e conscientização da população para com cada tipo de resíduo através de propagandas na televisão, programas educacionais nas escolas e projetos escolares.

Quando foi perguntado sobre quem gera mais resíduos 32\% dos garis responderam serem as crianças, $25 \%$ os jovens, $40 \%$ os adultos, e $3 \%$ os idosos, conforme a figura 2 . Essa questão foi exposta para se obter uma melhor compreensão sobre a era que o mundo está vivendo e o quanto é necessário trabalhar educação ambiental.



Figura 2: Relação entre a faixa etária e a produção de resíduos.

Os adultos, por serem os mais nocivos ao meio ambiente acabam influenciando as crianças e mesmo os jovens em seus comportamentos e isso se torna um dano muito sério ao equilíbrio da nossa biosfera. Essa falta de conscientização pode ser explicada pela época em que esses adultos viveram, uma vez que entre os anos 60 e 70 não se falava tanto em educação ambiental e em preservação, pois tudo isso estava começando a ser introduzido no país.

Foi constatado que o grupo social que menos descarta resíduos é o dos idosos, uma das explicações pode ser a expectativa de vida brasileira que gira em torno dos 65 anos de idade, um número relativamente baixo em relação a alguns países europeus, portanto, há uma população maior de jovens e adultos. Vale salientar também as pessoas de terceira idade que procuram se manter saudáveis e preservar o meio ambiente buscando muitas instruções a esse respeito.

Quando perguntado aos entrevistados se eles achavam que existia uma quantidade suficiente de lixeiras espalhadas pelo local em questão, 52\% afirmaram ser suficiente, enquanto que $44 \%$ apresentaram opinião contrária e $4 \%$ não sabiam ou preferiram não opinar. Diante disso, comprova-se a necessidade de uma preocupação mais ampla em agregar-se aos locais em questão, onde há uma grande circulação de pessoas, um maior número de recipientes destinados ao acondicionamento dos resíduos. Em contrapartida, sem a conscientização da população o trabalho se torna unilateral, uma vez que a conservação de tais acondicionadores depende essencialmente da sociedade.

É necessário investir em mais lixeiras na praia, na escola, no parque e nos centros comerciais, mas é de extrema relevância também a manutenção delas, pois em locais visitados 
como o Parque das Dunas a maioria dos entrevistados disse ser satisfatório número de lixeiras (80\%), porém enfatizaram as péssimas condições dos recipientes lá encontrados.

Ao interrogar-se a respeito da educação da população voltada para jogar os resíduos nas lixeiras, $80 \%$ dos entrevistados do Parque das Dunas disseram que a população joga o lixo nos locais destinados, enquanto que na praia de Ponta Negra esse resultado foi inverso, a grande maioria joga o lixo em qualquer lugar poluindo a praia. No IFRN, $60 \%$ dos garis consideram que o lixo está sendo depositado no lugar certo, já no Alecrim 100\% dos entrevistados afirmaram que a população não coloca os resíduos nos recipientes. Com isso, nota-se que embora tenha um grande fluxo de pessoas no Parque e no Instituto, as pessoas que circulam nesses locais se apresentam com um nível de preocupação maior com o ambiente, ao passo que os indivíduos que freqüentam a praia e o centro comercial em questão possuem um grau menor de preocupação com os destinos dos resíduos sólidos e o meio ambiente.

Com relação à separação adequada dos resíduos de acordo com o tipo de material (plástico, papel, vidro, etc), $40 \%$ dos participantes da pesquisa, sendo eles da praia de Ponta Negra e do Alecrim declararam não existir lixeiras voltadas para coleta seletiva nos respectivos locais. Enquanto no IFRN, $60 \%$ dos trabalhadores questionados atestaram que as pessoas não costumam depositar os resíduos nos recipientes destinados a cada tipo, enquanto que $30 \%$ se posicionaram de forma antagônica e os restantes disseram que depende do tipo de resíduo e de cada pessoa. Através desses números comprova-se que apesar da grande importância que a coleta seletiva apresenta, esta inexiste em boa parte da cidade do Natal, mas também possuir locais com as lixeiras separadoras não implica diretamente em coleta seletiva, como é o caso do IFRN onde a maior parte dos resíduos sólidos que são dispostos nas lixeiras para coleta seletiva não são reaproveitados como deveriam, uma vez que são coletados também pelo serviço de coleta do lixo da cidade, realizado pela Urbana.

Quanto à relação da sociedade com os garis, estes foram perguntados qual o tratamento que eles recebiam por realizar a limpeza dos locais em estudo, 64\% disseram ser bem tratados e apenas $12 \%$ relataram sobre maus tratos, os remanescentes declararam depender das pessoas com as quais lidam ou ser ignorado pelas pessoas. Nesse contexto, abordou-se ainda o fato de os garis sentirem diferenças no tratamento quando estavam com ou sem o fardamento e o resultado foi equitativo $48 \%$ afirmaram sentir diferenças e a mesma quantidade declarou não perceber diferenças e os $4 \%$ restantes disseram observar diferenças às vezes.

Nesse aspecto, a população natalense demonstra ser mais bem educada, tratando os trabalhadores da limpeza pública de forma, no mínimo, digna. Contudo essa realidade não está presente em todos os locais visitados, no Alecrim e na praia de Ponta Negra, em especial, os garis deram depoimentos de insatisfação com relação a acolhida das pessoas, a medida que no IFRN e Parque das Dunas os trabalhadores se mostraram mais satisfeitos quanto ao tratamento.

Quando os garis foram abordados com a questão referente a possibilidade de mudança comportamental da sociedade para com o lixo, responderam com segurança: $88 \%$ dos entrevistados acreditam que pode haver mudança, mas $12 \%$ pensam que isso não é possível. Os primeiros argumentaram que isso é possível devido ao poder da educação na formação de um indivíduo. Por outro lado, a minoria pensa que o desprezo dado às questões relacionadas ao lixo não mudará independente de qualquer proposta de educação, uma vez que cada pessoa tem o seu 
livre arbítrio e se ela não tem a consciência ambiental formada, dificilmente será influenciada por programas educacionais.

Como forma de solucionar essa problemática comportamental, foi apresentada aos garis a possibilidade da existência de leis mais rígidas, a fim de punir aqueles que não se comportassem como integrante do próprio meio ambiente; tendo em vista que todo ser humano tem amor a si próprio, ele não se autodestruiria. Os resultados foram os seguintes: $84 \%$ acreditam que uma legislação mais rígida poderia resolver esse problema ético, enquanto $16 \%$ acham ao contrário. Esses números refletem o quanto a sociedade ainda crê na eficiência da legislação quando aplicada e fiscalizada. Em compensação, o segundo grupo não confia mais no poder das leis, e como justificativa foi apresentado casos de leis que não conseguiram resolver o problema em questão. A exemplificação mais apresentada foi a da lei seca. Apesar do número de apreensões e atuações ter aumentado com a implantação da Lei Seca há exatos três anos, no dia 19 de junho de 2008, o número de mortes e acidentes não seguiu a mesma tendência em oito das maiores capitais brasileiras, segundo levantamento feito pela reportagem do portal Terra.

Mesmo sabendo da ocupação dos garis, eles são um grupo de pessoas que fazem parte da sociedade, logo eles foram questionados quanto à realização da separação do lixo em suas respectivas residências. Essas respostas compreendem, portanto, a um resultado subentendido, pois eles não consideraram a percepção do gari: $60 \%$ costumam separar o lixo e $40 \%$ não têm essa prática. Tomando como referencial a sociedade, esses resultados foram positivos. Aqueles que responderam que não organizam seu lixo conforme a composição deram a justificativa de que não há grupos de coleta seletiva no bairro onde residem.

O último questionamento diz respeito à problemática dos resíduos sólidos urbanos em seus aspectos socioambientais. Os entrevistados foram solicitados a comentar sobre os problemas relacionados ou causados pelo lixo. As respostas apresentadas foram, em sua maioria, ligadas aos problemas de saúde, principalmente por causa da proliferação dos vetores transmissores de doenças, como também o aspecto estético. Com esses resultados evidencia-se o desconhecimento ou esquecimento dos problemas de poluição ambiental, tais como de corpos d'água, do solo, do ar. A fim de tentar reverter este quadro é proposta a inserção da educação ambiental na sociedade como um todo, para conhecerem o lixo e todos os seus significados.

\section{CONCLUSÕES}

A partir do que foi exposto no presente artigo ficou claro que a população natalense não tem um conceito definido do que seria lixo, além de uma falha nas instruções sobre a sua coleta e reciclagem. Tendo esses pontos em vista é pertinente o enfoque do governo em uma maior quantidade de acondicionadores separadores bem como em educação e sensibilização da sociedade para com o nosso planeta. Além do governo, os demais líderes de instituições e empresas devem adotar também este enfoque, tornando-se sensíveis às questões ambientais. Mas, principalmente, é impreterível o desejo do indivíduo em conservar o planeta com suas ações e de fazer-se uso da ética como um instrumento de defesa do meio ambiente e de archotes de conhecimento para os olhos dos demais seres humanos.

Endossando os resultados expostos tem-se a percepção final de que o conhecimento dos garis, bem como da sociedade, sobre os resíduos sólidos se encontra centrado no bem-estar social, 
isto é, a preocupação ambiental ficou em segundo plano pela maioria dos entrevistados. O ambiente tem sido negligenciado e esquecido por pessoas que circulam frequentemente os centros comerciais, as praias, os parques e as escolas, elas simplesmente se esqueceram que fazem parte do meio ambiente e que também estão se prejudicando ao destinar os resíduos sólidos inadequadamente, pois elas sofrerão as consequências, até mesmo prejudiciais à saúde.

A postura da sociedade natalense não difere do comportamento do povo brasileiro como um todo diante do lixo e com tudo que está a ele relacionado. Por não apresentar uma educação ambiental solidificada, as pessoas não se preocupam em acondicionar corretamente seu rejeito se no local onde estiver não existir uma lixeira ao seu lado. Isso acontece, principalmente por se confiar no trabalho realizado pelo gari, o que garante a comodidade característica do perfil natalense.

Como vimos, toda problemática dos resíduos sólidos urbanos com vistas na sociedade é algo delicado de lidar. Mudar o modo de agir e pensar da maioria da população não é tarefa das mais fáceis de ser atingida, por isso devemos concentrar as nossas forças e investimentos na educação ambiental como meio de transformação social. Ela atua como um fator determinante na educação de crianças, jovens, adultos e idosos, fazendo com que estes tenham conhecimento não só do modo adequado de se dispor os resíduos, mas também da legislação que enquadra o tratamento deles.

\section{REFERÊNCIAS BIBLIOGRÁFICAS}

1. BONI, V.; QUARESMA, S. J. Aprendendo a entrevistar: como fazer entrevistas em ciências sociais. Revista Eletrônica dos Pós-graduandos em Sociologia Política da Ufsc, Santa Catarina, v. 2, n. 1, p.68-80, 2005

2. BRANDÃO, Z. Entre questionários e entrevistas. In: NOGUEIRA, M.A.; ROMANELLI, G.; ZAGO, N. (orgs.) Família \& escola. Rio de Janeiro: Vozes, 2000. P. 171-183.

3. BRASIL. Ministério do Meio Ambiente. Identidades da Educação Ambiental Brasileira. Brasília: Gráfica Gutenberg, 2004.

4. BRASIL. Ministério do Trabalho e Emprego. Tabela de ocupações. Disponível em: http://www.mte.gov.br/empregador/cbo/procuracbo/conteudo/tabela3.asp?gg=5\&sg=5\&gb $=2$. Acesso em: 15 jun. 2011 .

5. CARVALHO, I. C. M. Educação ambiental: a formação do sujeito ecológico. São Paulo: Cortez, 2004.

6. CARVALHO, I. C. M. Qual Educação Ambiental? Elementos para um debate sobre a educação ambiental e extensão rural, Agroecol. e Desenv. Rur. Sustent. Porto Alegre, v.2, n.2, abr./jun. 2001.

7. CUNHA, M. R. R. L. Risco e Consumo: a construção da identidade a partir do lixo. Fragmentos de Cultura, Goiânia, v. 19, n. 3/4, p.185-205, 2009.

8. D`ALMEIDA, M. L. O.; VILHENA, A. Lixo municipal: manual de gerenciamento integrado. 2. ed. São Paulo: IPT/CEMPRE, 2000. 370 p.

9. FERREIRA, A. B. H. Miniaurélio Século XXI: O minidicionário da língua portuguesa. 4a Rio de Janeiro: Nova Fronteira, 2000. 
10. GALBIATI, A. F. O Gerenciamento Integrado de Resíduos Sólidos e a Reciclagem. Mato Grosso do Sul, 2005.

11. MELAZO, G. C. Percepção ambiental e educação ambiental: uma reflexão sobre as relações interpessoais e ambientes no espaço urbano. Olhares \& Trilhas, Uberlândia, v. 6, n. 6, p.45-51, 2005.

12. NORONHA, I. O. Resíduos Sólidos Urbanos: A Percepção e o Comportamento Sócioambiental da População do Bairro Fernão Dias em Belo Horizonte, Minas Gerais. 2005. 113 p. Dissertação (Mestrado em Gestão e Auditoria Ambiental).

13. OlIVEIRA, K. A.; CORONA, H. M. P. A percepção ambiental como ferramenta de propostas educativas e de políticas ambientais. Anap Brasil, Curitiba, v. 1, n. 1, p.53-72, 2008.

14. PORTILHO, F. Representações sociais de profissionais: para além de estigmas, repulsas e tabus. Saúde e Direitos Humanos, Brasília, n. 3, p.135-148, 2006.

15. SANTOS, G. O.; SILVA, L. F. F. Estreitando nós entre o lixo e a saúde: estudo de caso de garis e catadores da cidade de Fortaleza, Ceará. Revista Eletrônica do Prodema, Fortaleza, v. 3, n. 1, p.83-102, jun. 2009.

16. SGORLON, D.; SILVA, J. E.; FERNANDES, V. A. Garis: Trabalho e dignidade. 59 f. Trabalho de Conclusão de Curso (Bacharelado) - Curso de Comunicação Social Com Habilitação em Jornalismo, Centro Universitário de Maringá, Maringá, 2008.

17. TAVARES, C.; FREIRE, I. M. "Lugar do lixo é no lixo": estudo de assimilação da informação. Ciência da Informação, Brasília, v. 32, n. 2, p.125-135, 2003.

18. UNB, PUC MINAS/IDHS, PNUD. Sustentabilidade ambiental: garantir a sustentabilidade ambiental. Belo Horizonte: PUC MINAS/IDHS, 2004. 